elsewhere on the basis of our clinical studies that there is much undesirable and unnecessary polypharmacy in the treatment of epilepsy. ${ }^{35}$ Prolonged follow-up will be of interest, but the present findings are in keeping with our view that the incidence of chronic toxicity can be reduced by careful monitoring of single-drug treatment.

We are grateful to Parke-Davis, Ciba-Geigy, and the Medical Research Council for financial support and to Dr A Johnson for statistical advice.

Reprint requests to EHR.

${ }^{1}$ Reynolds EH. Chronic toxicity of antiepileptic drugs. Ir Med $\mathcal{F}$ 1980; 7, suppl:45-51.

2 Shorvon SD, Chadwick D, Galbraith AW, Reynolds EH. One drug for epilepsy. Br Med f 1978; :474-6.

${ }^{3}$ Reynolds EH, Shorvon SD. Monotherapy or polytherapy for epilepsy? Epilepsia 1981 ;22:1-10

4 Shorvon SD, Reynolds EH. Anticonvulsant peripheral neuropathy: a clinical and electrophysiological study of patients on single drug treatment with phenytoin, carbamazepine or barbiturates. $\mathcal{f}$ Neurol Neurosurg Psychiatry 1982 (in press)

5 Shorvon SD, Reynolds EH. Reduction in polypharmacy for epilepsy. $\mathrm{Br}$ Med F 1979;ii:1023-5.

(Accepted 17 May 1982)

University Department of Neurology, King's College Hospital, London SE5 9RS

D I DELLAPORTAS, MD, honorary registrar

S D SHORVON, MB, MRCP, honorary registrar (present appointment: honorary senior registrar, National Hospital, Queen Square, London WC1)

A W GALBRAITH, MB, BCHIR, clinical assistant

$M$ LAUNDY, HNC, senior technician

E H REYNOLDS, MD, FRCP, consultant neurologist

Department of Clinical Pathology, King's College Hospital, London SE5 9RS

W J MARSHALL, MRCP, MRCPATH, consultant chemical pathologist

Division of Haematology, Northwick Park Hospital, Harrow, Middlesex

I CHANARIN, MA, FRCPATH, consultant haematologist

\section{Collapse of cervical spine treated by Down's Ace mark III halo assembly}

Treating patients with collapse of the cervical spine by applying Down's Ace mark III halo assembly is suitable only in terminal patients in whom pain has become intolerable and paraplegia threatens. When the secondary deposits are so widespread the prognosis is usually bleak, and radiation and chemotherapy have only a delaying action on the final result. With this degree of destruction of the vertebrae pain is intolerable, and the rigid support afforded by the halo effectively abolishes this and allows a person without paraplegia to be mobilised.

\section{Case report}

A 35-year-old woman was first seen in March 1975 for a breast lump that had been present for four years. Simple mastectomy and biopsy of the lump and the right axillary glands were carried out and showed a scirrhous carcinoma with spread to the axillary glands. A bone scan showed no abnormality, and she was referred for high-dose radiation (total 4000 rads). In July 1977 a nodule in the upper part of the right breast proved to be a recurrence, and by February 1978 there were palpable fixed glands in the axilla. Tamoxifen $20 \mathrm{mg}$ twice daily was started.

In December 1979 she fell downstairs and complained of neck pain. Radiography showed the body of the second cervical vertebra to be badly eroded. As a temporary measure the cervical spines of the second and third cervical vertebrae were wired together. This relieved the pain with the aid of a cervical collar until April 1981. After the wiring a further course of radiation was given.

Her condition continued to deteriorate, and from July 1980 to July 1981 she was given eight courses of fluoracil $500 \mathrm{mg}$ intravenously and vincristine $1 \mathrm{mg}$ intravenously at weekly intervals for four weeks. Nandrolone decanoate $50 \mathrm{mg}$ intramuscularly was given twice during the four-week course, and prednisolone $10 \mathrm{mg}$ twice daily was given over two weeks. By September 1981 she was in acute pain, which was relieved only by cervical traction in the horizontal position. Any movement was extremely painful. Radiography showed destruction of the upper three cervical vertebrae.

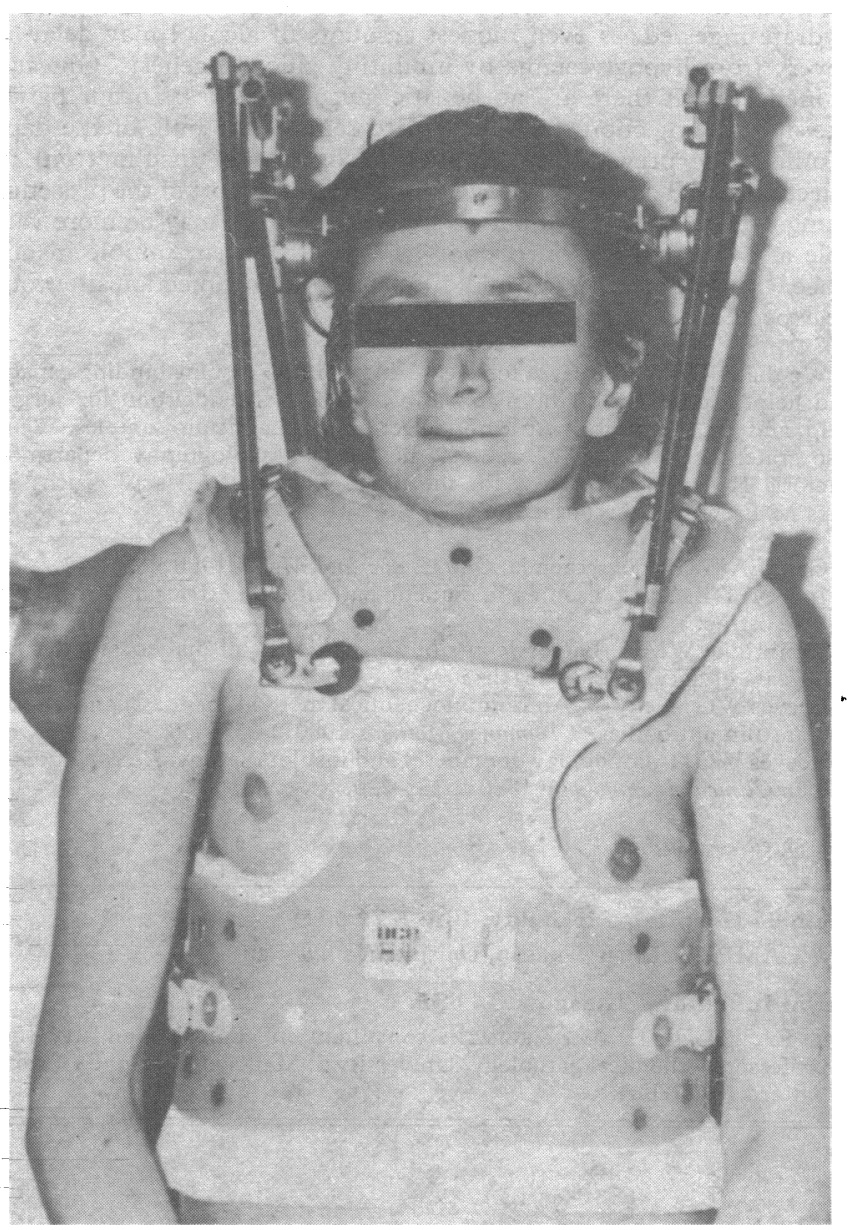

Halo apparatus in position.

The halo apparatus was applied in October under local anaesthesia (figure). With this apparatus she was able to sleep and to walk the length of the corridor. This was of considerable benefit, and she died in her sleep in November 1981.

\section{Comment}

Kevin and Harrington ${ }^{1}$ recently used methylmethacrylate to replace vertebral bodies and stabilise fracture dislocations of the spine caused by metastatic malignant disease. They stated: "The reader must be cautioned against over zealous application of the technique to all patients with vertebral involvement by metastatic lesions. The vast majority of symptomatic vertebral lesions can be controlled by local irradiation alone. Most of the vertebrae that subsequently collapse do not cause neural impingement and will become asymptomatic with a combination of local radiotherapy and temporary external support."

Only rare cases will be suitable for treatment by this technique. When the cervical spine is affected the halo apparatus offers pain relief by a fairly painless and simple method.

${ }^{1}$ Kevin D, Harrington MD. The use of methylmethacrilate for vertebral body replacement and anterior stabilisation of pathological fracture dislocations of the spine due to metastatic malignant disease. $\mathcal{f}$ Bone foint Surg ( $\mathrm{Am})$ 1981 ;63A:36-45.

(Accepted 18 May 1982)

York District Hospital, York

D W M HAW, BSC, FRCS, orthopaedic surgeon 